\title{
Non-Surgical Treatment of Cesarean Scar Pregnancy: Two Case Reports
}

\author{
Mojgan Barati ${ }^{1,} ;$ Kobra Shojayi $^{1}$; Farideh Moramezi ${ }^{1}$; Nafiseh Hoseiny Moghadam ${ }^{1}$ \\ ${ }^{1}$ Fertility, Infertility and Perinatology Research Center, Imam Khomeini Hospital, Medicine Faculty, Ahvaz Jundishapur University of Medical Sciences, Ahvaz, IR Iran \\ ${ }^{*}$ Corresponding author: Mojgan Barati, Fertility, Infertility and Perinatology Research Center, Imam Khomeini Hospital, Medicine Faculty, Ahvaz Jundishapur University of Medical \\ Sciences, Ahvaz, IR Iran. Tel: +98-9161187090, Fax: +98-6133335399, E-mail: barati_m70@yahoo.com
}

Received: March 7, 2015; Accepted: March 25, 2015

Keywords: Scar; Pregnancy; Treatment

\section{Dear Editor,}

Cesarean scar pregnancy refers to implantation within the myometrium of a prior cesarean delivery scar. Its incidence approximates 1 in 2000 normal pregnancies and has increased alongside the cesarean delivery rate (1).

Several treatment options are available, but none of them are standard. Because of the risk of uterine rupture and uncontrollable bleeding, hysterectomy is indicated. However, several types of conservative treatments have been used such as dilation, curettage, and excision of trophoblastic tissue using laparotomy or laparoscopy $(2,3)$.

Fertility preserving options include systemic or locally injected methotrexate (MTX), either alone or combined with conservative surgery (4).

There are two cases of cesarean scar pregnancies, which were treated completely with locally injected methotrexate (in one case) and potassium hydrochloride (in the other one).

Case 1: She was a 33-year-old woman with a history of one previous $\mathrm{C} / \mathrm{S}$ presented with spotting per vagina of 9 weeks' amenorrhea. Transvaginal sonography showed a $33 \mathrm{~mm}$ gestation sac with fetal heart and yolk sac at lower segment of uterine at the location of previous C/S scar. No intrauterine gestational sac, adnexal masses, or free fluid was noted on sonography. The first $\beta$-hcG titer ( $\beta$ subunit of human chorionic gonadotropin) of the patient was $58000 \mathrm{IU} / \mathrm{L}$. She was offered for observation. Her second set of $\beta$-hcG increased to $110500 \mathrm{IU} / \mathrm{L}$. Two doses of MTX with 48 hours interval were prescribed for her. In her follow up, the repeated transvaginal sonography showed similar findings with fetal heart activity.

The patient did not experience any symptom of pain or bleeding at this point and was clinically stable. She was offered the option of injection KCL with sonography guidance. Next day after KCL injection, the fetal heart was not detected. The patient was observed for one more week and then discharged with weekly checking of $\beta$-hcG titer. At the third week of follow-up, her $\beta$-hcG level was under $1000 \mathrm{IU} / \mathrm{L}$. The level of $\beta$-HcG became negative after 4 weeks and ectopic pregnancy mass in cesarean scar disappeared after 5 months.

Case 2: She was 34 years old with a history of one previous $\mathrm{C} / \mathrm{S}$ who was presented with spotting per vagina of 6 week's amenorrhea. Transvaginal sonography showed an $18 \times 20 \mathrm{~mm}$ gestation sac with fetal heart and yolk sac at lower segment of uterine at the location of the previous $\mathrm{C} / \mathrm{S}$ scar. No intrauterine gestational sac, adnexal masses, or free fluid was noted on sonography. The patient's first set of serum $\beta$-hcG titer was 14480 IU/L. She was offered for observation. Her second set of $\beta$-hcG increased. Two doses of systemic MTX were prescribed for her. In follow up, the repeated transvaginal sonography showed similar findings with fetal heart activity.

The patient did not experience any symptom of pain or bleeding at this point and was clinically stable. She was offered the option of MTX injection with sonography guidance. In her follow-up after injection, the fetal heart was not detected. She was discharged with weekly checking of $\beta$-hcG titer. At the second month of follow-up, her $\beta$-hcG level was undetectable. Cesarean scar mass disappeared after 6 months and she became pregnant with normal implantation of pregnancy after 2 years.

\section{Acknowledgements}

The authors wish to acknowledge the efforts of Dr Masoud Hemadi (Vice Chief of the Fertility, Infertility, and Perinatology Research Center, Ahvaz Jundishapur University of Medical Sciences, Ahvaz, IR Iran) for his generous help in conducting the study.

\section{References}

1. Ash A, Smith A, Maxwell D. Caesarean scar pregnancy. BJOG Int J Obstet Gynecol. 2007;114(3):253-63.

Copyright (C) 2015, Ahvaz Jundishapur University of Medical Sciences. This is an open-access article distributed under the terms of the Creative Commons Attribution-NonCommercial 4.0 International License (http://creativecommons.org/licenses/by-nc/4.0/) which permits copy and redistribute the material just in noncommercial usages, provided the original work is properly cited. 


\section{Barati M et al.}

2. Seow KM, Cheng WC, Chuang J, Lee C, Tsai YL, Hwang JL. Methotrexate for cesarean scar pregnancy after in vitro fertilization and embryo transfer. A case report. J Reprod Med. 2000;45(9):754-7.

3. Godin PA, Bassil S, Donnez J. An ectopic pregnancy developing in a previous caesarian section scar. Fertil Steril.1997;67(2):398-400. 4. Shen L, Tan A, Zhu H, Guo C, Liu D, Huang W. Bilateral uterine artery chemoembolization with methotrexate for cesarean scar pregnancy. Am J Obstet Gynecol. 2012;207(5):386 e1-6. 